\title{
Salmon Calcitonin Induces Pituitary Tumor in Rats
}

\author{
Jun ISHII, Shigehiro KATAYAMA, AKIRA ITABASHI, \\ Мотонide TAKAHAMA*, AND ShoJi KAWAZU** \\ The Fourth Department of Medicine and *The Second Department \\ of Pathology, Saitama Medical School, Saitama 350-04, \\ and **The Second Department of Medicine, School of Medicine, \\ Gunma University, Gunma 371, Japan
}

\begin{abstract}
Calcitonin is widely used in the treatment of post-menopausal osteoporosis. The present study was designed to investigate the effects of salmon calcitonin (SCT) on the incidence of the pituitary tumors in Sprague-Dawley (SD) rats. Subcutaneous injections of SCT at a dose of $160 \mathrm{IU} / \mathrm{kg} / \mathrm{day}$ for 6 months reduced body weight and induced one pituitary hyperplasia and three pituitary adenomas in 4 of 5 animals, while 5 controls did not show any changes. Prolactin-positive cells were located at the periphery of the affected pituitaries adjacent to the prolactin-negative adenomas. In addition, serum concentrations of prolactin and TSH were lower than in the controls, although serum calcium or LH levels were not significantly different from the controls. Among 7 animals treated with SCT for 6 months followed by no medication for another 6 months, 5 adenomas were detected, one of which had invasive growth toward the adjacent tissue, whereas only one adenoma was found in 9 controls. These results suggest that SCT administration at a high dose may induce the formation of pituitary adenoma, or may accelerate the development of spontaneous pituitary adenomas, some of which show frequent mitotic figures and invasive growth into the surrounding tissue, possibly resulting in malignant transformation. This indicates the need for caution in considering whether calcitonin injections into patients with osteoporosis as well as Paget's disease may induce such pituitary tumors.
\end{abstract}

Key words: Pituitary tumor, Salmon calcitonin, Osteoporosis, SD rats.(Endocrinol Japon 38: 705-709, 1991)

CALCITONIN (CT) is now widely used to treat patients with osteoporosis [1]. The rationale for this therapy is the observation that CT inhibits calcium resorption from bone, possibly through the inhibition of osteoclast-mediated bone functions, which include lysosomal enzyme changes, mineral release and degradation of collagen $[2,3]$. Salmon calcitonin (SCT) has been commercially available in many countries including the United States and United Kingdom and recently has been made available in Japan. Adverse reactions reported thus far include allergic reactions such as urticaria and exanthema, gastrointestinal symp-

Received: October 21, 1991

Accepted: November 22, 1991

Correspondence to: Dr. Jun ISHII, The Fourth Department of Medicine, Saitama Medical School, 38 Morohongo, Moroyamacho, Iruma-gun, Saitama 350-()4, Japan toms, mainly nausea and vomiting, and circulatory symptoms such as flushing, palpitation and chest discomfort [4]. We have found that long-term administration of SCT to Sprague-Dawley (SD) rats induces the occurrence of anterior pituitary tumors. In the present study, we investigated the effects of long-term SCT administration to rats on growth, pituitary weight and histological changes, and serum concentrations of calcium and selected pituitary hormones.

\section{Materials and Methods}

Male SD rats aged 7 weeks were obtained from Charles River Japan. SCT, kindly donated by Yamanouchi Pharmaceutical Co., was dissolved in $1 \%$ gelatin, $0.2 \%$ phenol and $0.85 \% \mathrm{NaCl}(\mathrm{pH} 3.2)$ 
and administered via subcutaneous injections at a daily dose of $160 \mathrm{IU} / \mathrm{kg}(\mathrm{n}=12)$. Control animals $(\mathrm{n}=14)$ received only vehicle at $2 \mathrm{~m} / \mathrm{kg} /$ day. Body weight was recorded monthly. After 6 months, 5 animals from each group were sacrificed. A second arm of the study involved a 12-month period consisting of treatment with SCT (or vehicle) for 6 months, followed by a 6 -month "medication-free" interval. All animals were sacrificed at the end of 12 months. The pituitary gland was weighed, fixed in $10 \%$ formalin, dehydrated in alcohol, and embedded in paraffin. Thin sections $(4 \mu \mathrm{m})$ were stained with hematoxylin and eosin for histological study. Adenomas were characterized by monotonous proliferation of chromophobic cells with large round nuclei and a single prominent nucleolus. For immunohistochemical analysis, the sections were rehydrated and incubated with antiserum against rat PRL at a 1:100 dilution. In the subsequent steps, biotinylated sheep antisera against rabbit immunoglobulin $G$ were used to visualize PRL-containing cells, employing an avidin-biotin-peroxidase complex (Vecstatin ABC kit, Vector Labs, Burlingame, California) [5]. Plasma levels of PRL, TSH and LH were determined by the specific radioimmunoassay as reported previously [6, 7] and expressed as $\mathrm{ng} / \mathrm{m} l$. The kits were kindly donated by NIDDK and the reference preparation was RP-1 for TSH and RP-2 for PRL and LH, respectively.

All data are expressed as the mean \pm SEM. Statistical analysis was done by Student's $t$-test or $\chi^{2}$-analysis.

\section{Results}

Initial body weight was the same in both groups $(242 \pm 2.0 \mathrm{~g}$ in controls vs. $242 \pm 2.1 \mathrm{~g}$ in SCTinjected group). However, the 6-month subcutaneous administration of SCT significantly suppressed body weight gain $(573 \pm 18.6 \mathrm{~g})$ in the treated group in comparison to the controls $(642 \pm 4.3 \mathrm{~g}, \mathrm{p}<0.01)$. This difference in body weight disappeared after another 6 months with-

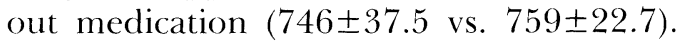

As shown in Table 1, the weight of the pituitary glands in the SCT-treated group tended to be greater than that of the control animals at 6 months as well as at 12 months; the difference, however, was not statistically significant. Serum calcium concentrations were similar in both treated and control groups. Serum PRL and TSH levels in the SCT-treated group were significantly lower than in the controls.

Table 2 shows the results of the histological studies of the pituitary glands. Control animals sacrificed after 6 months did not show any specific changes. However, 4 of 5 pituitaries obtained from animals treated with SCT had abnormal findings as indicated in Table 2. A typical hematoxylineosin staining pattern obtained from the pituitary gland of a SCT-treated rat is illustrated in Fig. 1. In addition, typical immunohistochemical staining clearly demonstrated that PRL-positive lactotrophs were located peripherally in the pituitaries studied, and tumor cells were not stained with PRL-antibody as shown in Fig. 2. In control rats aged about 14 months, one adenoma was found

Table 1. Pituitary weight and serum concentrations of calcium, PRL, TSH and $\mathrm{LH}$ in control and SCT-injected rats

\begin{tabular}{|c|c|c|c|c|}
\hline \multirow[b]{3}{*}{$\mathrm{n}$} & \multicolumn{2}{|c|}{ After 6 months } & \multicolumn{2}{|c|}{$\begin{array}{l}\text { After } 12 \text { months } \\
\text { (6-month medication plus } \\
\text { 6-month medication-free) }\end{array}$} \\
\hline & Control & SCT & Control & SCT \\
\hline & 5 & 5 & 9 & 7 \\
\hline $\begin{array}{l}\text { Weight of Pitui- } \\
\text { tary gland (mg) }\end{array}$ & $12.5 \pm 0.9$ & $15.4 \pm 2.2$ & $16.1 \pm 2.0$ & $26.5 \pm 6.3$ \\
\hline Calcium $(\mathrm{mg} / \mathrm{d} l)$ & $11.2 \pm 0.2$ & $11.4 \pm 0.2$ & $9.8 \pm 0.2$ & $10.2 \pm 0.1$ \\
\hline PRL $(\mathrm{ng} / \mathrm{m} l)$ & $148.0 \pm 16.0$ & $65.8 \pm 10.3^{* *}$ & N.E. & N.E. \\
\hline TSH $(\mathrm{ng} / \mathrm{m} l)$ & $1.5 \pm 0.1$ & $1.1 \pm 0.1 *$ & N.E. & N.E. \\
\hline $\mathrm{LH}(\mathrm{ng} / \mathrm{ml})$ & $5.8 \pm 0.9$ & $4.4 \pm 0.7$ & N.E. & N.E. \\
\hline
\end{tabular}

Each value indicates the mean \pm SEM. N.E.: not examined.

$*: \mathrm{p}<0.05, * *: \mathrm{p}<0.01$. 
Table 2. Incidence of focal chromophobe hyperplasia or adenoma in controls or rats treated with SCT for 6 months

\begin{tabular}{|c|c|c|c|c|}
\hline & & Normal & Hyperplasia & Adenoma \\
\hline \multicolumn{5}{|c|}{ Immediately after 6-month medication } \\
\hline Control & $(n=5)$ & 5 & 0 & 0 \\
\hline SCT-treated & $(n=5)$ & 1 & 1 & 3 \\
\hline \multicolumn{5}{|c|}{$\begin{array}{l}\text { After } 12 \text { months } \\
\text { (6-month medication plus } \\
6 \text {-month medication-free) }\end{array}$} \\
\hline Control & $(\mathrm{n}=9)$ & 8 & 0 & 1 \\
\hline SCT-treated & $(\mathrm{n}=7)$ & 1 & 1 & $5^{\#}$ \\
\hline
\end{tabular}

The incidence of pituitary adenomas was higher in SCT-treated group at either age $\left(p<0.05\right.$ at 6 months, $p<0.01$ at 12 months). ${ }^{\#}$ One of 5 adenomas showed invasive growth into adjacent tissue, suggesting of malignant changes.

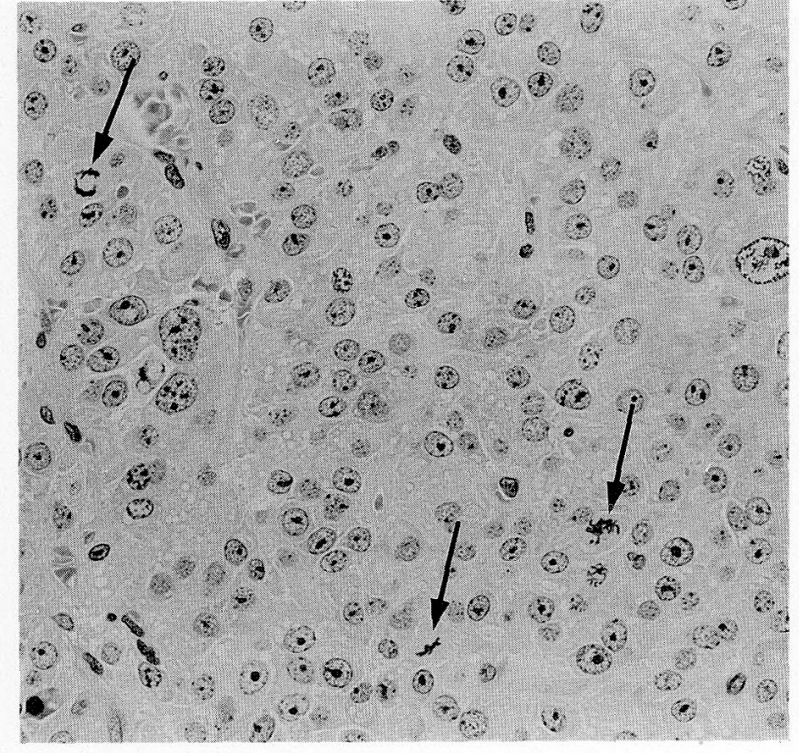

Fig. 1. Typical hematoxylin and eosin staining of the anterior pituitary gland obtained from male SD rats treated with salmon calcitonin at $160 \mathrm{IU} / \mathrm{kg} /$ day for 6 months, followed by a 6 -month medication-free interval. Many mitotic figures (arrows) are observed $(100 \times)$.

out of 9 glands examined. However, we observed one hyperplasia and 5 adenomas out of 7 SCT treated 14-month-old animals. Thus, the incidence of pituitary hyperplasia and adenoma was significantly higher in SCT-treated animals in comparison with controls either after SCT injections for 6 months $(p<0.05)$ or after 6 months of treatment followed by a 6-month medication-free period $(p<0.01)$. Of interest is the observation that one of

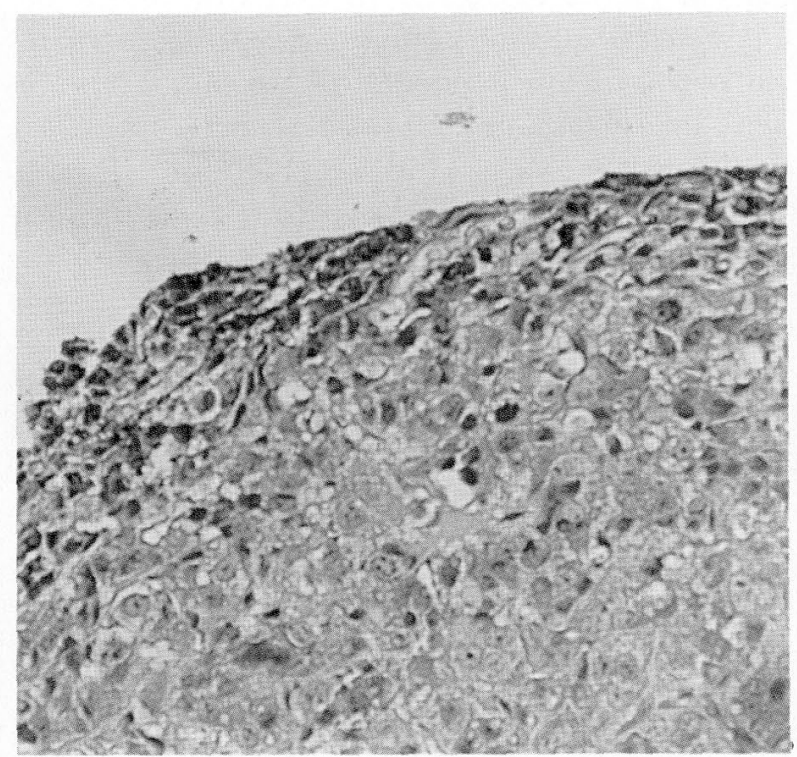

Fig. 2. Immunohistochemical staining of the pituitary gland obtained from male SD rats treated with salmon calcitonin at $160 \mathrm{IU} / \mathrm{kg} /$ day for 6 months. Prolactin positive-cells are located peripherally adjacent to adenoma cells, which are prolactinnegative $(100 \times)$.

5 adenomas in SCT-treated 14-month-old rats showed abundant mitotic figures and invasive growth into the adjacent tissue.

\section{Discussion}

The prescnt study demonstrates that long-term injections of SCT in rats may induce pituitary 
abnormalities. These changes include hyperplasia and adenoma. The peripheral distribution of PRL-positive cells and the immunohistochemically negative staining of the tumors strongly suggest that these tumors may be nonfunctioning chromophobe adenomas. These observations are supported by the finding of lower plasma levels of PRL and TSH in the SCT-treated group, which may reflect a mild hypopituitarism resulting from dysfunction of normal pituitary cells by tumor expansion. Reduced body weight gain during the SCT injections may be attributed to such hormonal changes or to some other toxic effect of SCT, since the amount of SCT utilized in the present study $(160 \mathrm{IU} / \mathrm{kg} /$ day $)$ was extremely high in comparison to the usual dose in humans (20-30 IU/person/week). In our present study, we did not observe a high incidence of pituitary tumors in control rats. However, it is well known that the incidence of pituitary tumor in SD rats increases with age [8]. The incidence of spontaneous pituitary adenoma in male $\mathrm{SD}$ rats has been reported to be from $24 \%$ to $85 \%$ in animals more than 16 months old $[8,9]$. There is also a slight difference from one strain to another. In Fischer 344 rats, the incidence has been reported to be $14.7-24 \%$ at the age of 6-36 months [8]. The first arm of our study was terminated at about 8 months; the second arm of the study was terminated at 14 months, following administration of SCT from weeks 7 to 55 . This is one of the reasons why we did not observe a higher incidence of pituitary tumors in the control animals. It is therefore very likely that long-term SCT injections at very high doses may induce the formation of pituitary adenomas in rats. Alternatively, SCT may accelerate the development of spontaneous pituitary adenomas.

The exact mechanism of pituitary tumor induction is not understood. However, some cases arise from prolonged hypersecretion resulting from target endocrine gland ablation or may occur as one component of the familial multiple endocrine neoplasia syndrome (MEN type I). In addition, long-term estrogen administration to rats is a well established method for producing PRL-secreting pituitary adenomas $[10,11]$. Recent evidence suggests that some of the effects of high estrogen may include suppression of tuberoinfundibular dopaminergic neuron activity, leading to the initial proliferation of the PRL-secreting cells [12]. $\mathrm{GH}_{3}$ cells, which have been used extensively as a model to study the secretion of PRL or growth hormone $(\mathrm{GH})$, are also derived from a radiation-induced rat pituitary tumor [13]. At the present time, the exact mechanism of SCT-induced pituitary adenoma is unknown. Although we could not demonstrate a calcium-lowering effect of SCT when blood samples obtained $24 \mathrm{~h}$ after the last injection of SCT were utilized for serum calcium levels, a decrease in serum calcium levels induced by SCT injection may have some pathophysiological actions to initiate the development of pituitary adenomas. In addition, diverse effects on hormone release from the pituitary or the pancreas have been reported. Such changes may stimulate the development of pituitary adenomas. Further studies are needed to clarify the exact mechanisms of SCT-induced pituitary adenomas. Furthermore, the species difference in SCT-induced pituitary adenomas as well as the potency of CT derived from different sources to induce pituitary adenomas should be investigated.

Fortunately, there has been no report to date of the induction of pituitary adenomas in humans resulting from long-term administration of calcitonin. Whatever the mechanisms, however, we must consider whether patients treated with calcitonin, for not only osteoporosis but also Paget's disease, may develop pituitary adenomas or adenocarcinomas at a later date.

\section{References}

1. McDermott MT, Kidd GS (1987) The role of calcitonin in the development and treatment of osteoporosis. Endocrine Rev 8: 377-390.

2. Chambers TJ, Magnus CJ (1982) Calcitonin alters behaviour of isolated osteoclasts. J Pathol 136: 27-39.

3. Holtrop ME, King GJ (1977) The ultrastructure of the osteoclast and its functional implications. Clin
Orthop 123: 177-196.

4. Zorzin L, Capone M (1984) Post-menopausal osteoporosis: Therapeutic and side effects of different calcitonins. Cur Ther Res 36: 473-482.

5. Hsu S-M, Raine L, Fanger H (1981) Use of avidin-biotin-peroxidase complex (ABC) in immunoperoxidase techniques: A comparison between $\mathrm{ABC}$ and unlabelled antibody (PAP) proce- 
dures. J Histochem Cytochem 29: 577-580.

6. Katayama S, Fishman J (1983) Inhibition of phasic but not tonic pituitary sectretion by 2 hydroxyestrone in the rat: Evidence of action as an oestrogen antagonist. J Endocrinol 98: 103-112.

7. Yanagisawa M, Fukazawa N, Hase K, Miura S, Sakatsume Y, Iitaka M, Hara Y, Negishi K, Ishii J (1990) Biological activity of TSH in streptozotocin diabetic rats. Tohnyobyo Doubutsu (Diabetic Animals) 4: 68-73 (In Japanese).

8. McComb DJ, Kovacs K, Beri J, Zak F (1984) Pituitary adenomas in old Sprague-Dawley rats: A histologic, ultrastructural, and immunocytochemical study. JNCI 73: 1143-1 166.

9. Andersson P (1969) High incidence of chromophobe pituitary adenoma-like lesions in an inbred Sprague-Dawley breeding rat colony. Acta Vet Scand 10: 111-117.

10. Furth J, Clifton KH, Gadsen EL, Buffet RF (1965)
Dependent and autonomous mammotropic pituitary tumors in rats: Their somatotropic features. Cancer Res 16: 608-616.

11. Wilklund JA, Gorkski RJ (1982) Genetic differences in estrogen-induced deoxyribonucleic acid synthesis in the rat pituitary: Correlations with pituitary tumor susceptibility. Endocrinology 111: 1140-1149.

12. Morgan WW, Steger RW, Smith MS, Bartke A, Sweeney CA (1985) Time course of induction of prolactin-secreting pituitary tumors with diethylstilbestrol in male rats: Response of tuberoinfundibular dopaminergic neurons. Endocrinology 116 : 17-24.

13. Tashjian AH (1979) Clonal strains of hormoneproducing pituitary cells. In: Jakoby WB, Pastan IH (eds) Methods in Enzymology. Academic Press, New York, 58: 527-535. 